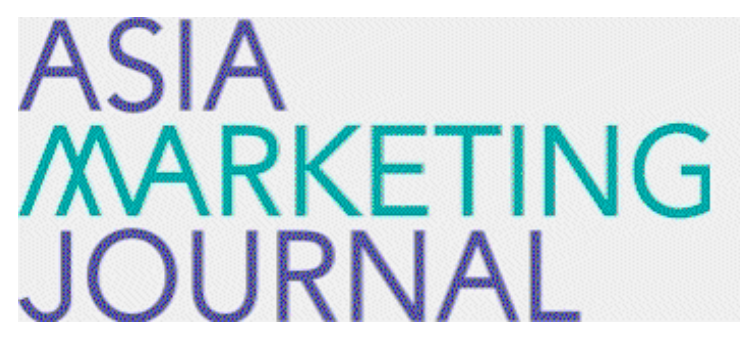

ASIA MARKETING JOURNAL

Volume 10 | Issue 1

Article 4

4-30-2008

\title{
구매자와 판매자의 용의가격 차이에 제품유형과 소비자의 목적지 향성이 미치는 영향
}

Sung Youl Jun

Tae Wook Ju

Hyo Ryung Cho

Follow this and additional works at: https://amj.kma.re.kr/journal

Part of the Marketing Commons

\section{Recommended Citation}

Jun, Sung Youl; Ju, Tae Wook; and Cho, Hyo Ryung (2008) "구매자와 판매자의 룡의가격 차이에 제품 유형 과 소비자의 목적지 향성이 미치는 영향," Asia Marketing Journal: Vol. 10 : Iss. 1 , Article 4.

Available at: https://doi.org/10.53728/2765-6500.1209

This Article is brought to you for free and open access by Asia Marketing Journal. It has been accepted for inclusion in Asia Marketing Journal by an authorized editor of Asia Marketing Journal. 


\title{
구매자와 판매자의 용의가격 차이에 제품유형과 소비자의 목적지향성이 미치는 영향
}

\section{The Effect of Regulatory Focus and Product Type on the Difference in Acceptable Prices between Buyers and Sellers}

\author{
전 성 률(Jun, Sung Youl)* \\ 주 태 욱 $(\mathrm{Ju}, \mathrm{Tae} \text { Wook })^{* *}$ \\ 조 효 령(Cho, Hyo Ryung) $)^{* * *}$
}

본 연구에서는 소유효과(endowment effect)와 손실희피(loss aversion)성향에 기인한 판매자의 판 매용의가격(willing-to-sell price: WTS) 과 구매자의 지불용의가격(willing-to-pay price: WTP) 간의 차이에 관한 기존 연구를 최근 점점 더 소비자들이 경헙하고 있는 새로운 유통경로인 온라인 경매라 는 거래상황에서 재검증하였으며, 동시에 이러한 판매자와 구매자의 용의가격의 차이에 조절적 영향 을 주는 요인으로, 이득(gain)과 손실(loss)에 대한 소비자들의 휴리스틱적인 성향과 관련된 기존 연 구결과들을 바탕으로 하여, 제품 유형(product type)과 소비자가 가지고 있는 목적 지향성 (goal orientation)이라는 추가적인 조절변수들의 효과를 살펴보았다.

실헙결과, 기존연구와 마찬가지로 판매자들이 제시하는 용의가격(WTS)이 구매자들이 지불하고자 하는 용의가격(WTP)보다 높았으며, 이 두 가격의 차이는 거래되는 제품이 소비자의 입장에서 실용 적인(utilitarian product) 가치를 갖는 제품일 때보다 쾌락적인(hedonic product) 가치를 갖는 제품일 때, 또한 거래에 참여한 소비자가 향상 목적(promotion goal)을 가지고 있을- 때보다 예방 목적 (prevention goal)을 가지고 있을 때 더욱 두드러지는 것으로 나타났다. 마지막으로, 본 연구결과의 이론적 및 실무적 시사점, 그리고 본 연구의 한계점 및 향후 연구방향에 대해서 논의하였다.

핵심개념: 가격협상, 지불용의가격, 판매용의가격. 실용적 제품, 캐락적 제품, 향상목적, 예방목적

\footnotetext{
* 서강대학교 경영대학 교수(syjun@sogang.ac.kr)

** 서강대학교 경영대화 박사과정(chutae78@hanmail.net), 교신저자

*** 서강대학교 경영대학 석사(hr314@hanmail.net)
} 


\section{I. 서 론}

"소비자 참여"가 하나의 키워드로 거론되는 Web 2.0 시대와 잘 어울리는 유통채널의 형태 로 인터넷 상에서 소비자 개인의 물건을 자유 롭게 팔거나, 살 수 있는 '옥션(Auction: www. auction.co.kr)'과 같은 인터넷 경매 싸이트를 생각해 볼 수 있다. 이러한 싸이트의 거래 모습 을 살펴보면 같은 물건에 대해서 그 물건을 사 려고 하는 사람은 최대한 싼 가격으로 사기 위 하여 최대한으로 낮은 가격을 제시하고 있는 반면에, 그 물건을 팔려는 사람은 최대한 비싼 가격으로 팔려고 하며 심지어 본인의 마음에 들지 않는 정도의 낯은 가격이 제시되었을 경 우에는 그 거래를 퐈기시키기도 한다. 또한, 부 동산을 거래하는 경우 똑같은 집인데도 불구하 고, 그 집을 사려는 사람은 보다 싸게 구입하려 고 하며, 그 집을 팔려는 사람은 보다 많은 돈 을 받기위하여 높은 가격을 제시한다. 비단 인 터넷 경매 싸이트나 부동산 거래예서 뿐만 아 니라 우리가 주위에서 흔히 볼 수 있는 재래시 장에서도 위에 언급한 거래행태를 볼 수 있다.

기존 연구에 따르면 이렇게 동일한 제품에 대 하여 그 제품을 판매하려는 사람이 적절하다고 판단하는 가격(willing-to-sell price; 이하 WTS) 과 그 제품을 구매하려는 사람이 적절하다고 판 단하는 가격(willing-to-pay price; 이하 WTP) 이 다른 원인은 단순히 판매자는 더 많은 금전 적인 이득을 얻으려고 하고, 구매자는 더 적은 금전적인 손살을 얻으려 하는 경제적인 이유뿐 만 아니라. 판매자와 구매자가 동일 제품의 가 치를 다른 시각에서 지각하게 되는 심리적인
이유에서도 기인함을 알 수 있다. 예를 들어, 사람들은 똑같은 사낭 허가권에 대한 구입 의 향 가격은 평균적으로 $\$ 31$ 을 제시했지만, 판매 의향 가격은 평균적으로 $\$ 143$ 을 제시하였으며 (Herberlein and Bishop 1985), Kahneman et al.(1990)의 연구를 살펴보면 같은 제품에 대한 평균적인 판매 가격이 평균적인 구매 가격에 비하여 2 배 정도 높은 것으로 나타났다. 이러 한 현상에 대하여 Thaler(1980)는 소유효과 (endowment effect)를 그 이유로 제시하고 있 다. 즉, 어떤 제품을 이미 소유하고 있는 사람 이 해당 제품에 대해 느끼는 가치가 그 제품을 향후 소유하려는 사람이 느끼는 가치보다 크다 는 것이다. 따라서 제품을 이미 소유하고 있는 사람인 판매의향자는 그 제품을 사고자 하는 구매의향자에 비하여 그 제품에 대해 보다 큰 가치를 지각하게 되며, 결국 구매의향자가 평가 하는 것보다 높은 가격을 제시하게 된다는 것 이다. 이와 유사한 맥락으로, 이러한 판매자와 구매자의 수용가격 차이는 사람들의 위험회피 (loss aversion) 성향을 통해서도 설명될 수 있 다. 판매자의 입장에서, 소유하고 있던 제품을 포기하는 것은 손실(loss)로 지각되겠지만, 구매 자의 입장에서 같은 제품을 소유할 수 있는 기 회를 놓치는 것은 포기된 이득(forgone gain)으 로 지각될 것이다. 이러한 상황을 사람들은 이 득보다는 손실에 더욱 민감하다는 위험회푀 성 향의 시각에서 조명해 보면, 가지고 있던 물건 을 포기하는 것이 동일한 물건을 소유할 수 있 는 기회를 놓치는 것보다 더욱 아깝게 느껴진 다는 것을 의미하고, 결국 이는 판매자의 제시 가격이 구매자보다 높게 책정될 가능성을 애기 해 준다(Bar-Hillel and Neter 1996; Kahneman 
and Tversky 1979; Tversky and Kahneman 1991).

그러나 이러한 판매자와 구매자의 용의가격 차이의 정도는 항상 일정한 비율 혹은 일정한 크기로 나타나는 것은 아니다. 경우에 따라서는 그 차이가 좁혀질 수도, 혹은 넓어질 수도 있는 것이다. 그리고 이러한 조절적인 역할을 하는 상황 혹은 변수에 대한 연구는 판매자와 구매 자 간의 가격협상을 원활하게 이끌어서 거래의 성사확률을 높이는 협상전랴적인 측면에서 매 우 중요하다고 할 수 있다. 이와 관련하여서 기 존 연구에서는 이러한 판매가격과 구매가격의 차이에 영향을 줄 수 있는 요인으로 차별적인 정박효과(differential anchoring effect)를 제시 하고 있다(Simonson and Drolet 2004). 정박효 과(anchoring effect)란 사람들은 어떤 값에 대 해 추정할 때 일반적으로 그들에게 제시된 어 떤 초기값에 기초(anchoring)한 후 이에 대한 조정(adjustment)을 거쳐서 최종적인 추정치를 산출한다는 것이다(Tversky and Kahneman 1974). 이 연구에 따르면 구매자의 경우는 구매 의향 가격을 결정할 때 해당 제품과 관련된 외 부적인 준거가격(reference prices)에 의해 보 다 많이 영향을 받고, 판매자의 경우는 판매 의향 가격을 결정할 때 외부적 준거가격 보 다는 제품에 대해 본인이 느끼는 주관적인 가치(subjective value)에 의해 더욱 영향을 받는다는 것이다. 즉, 구매자가 제시하는 가격 이 판매자가 제시하는 가격에 비하여 정박 효 과(anchoring effect)에 보다 쉽게 영향을 받게 되어, 외부적인 준거가격의 제시여부 및 그 수 준은 판매자와 구매자의 용의가격에 차별적인 영향을 주게 되어, 결국 두 가격의 차이에 조절
적인 영향을 줄 수 있다는 것이다.

본 연구에서는 우선 기존 연구를 확장하여 같 은 물건에 대하여 구매자가 제시하는 가격, 즉, 지불용의가격(WTP)과 판매자가 제시하는 가 격, 즉, 판매용의가격(WTS)의 차이에 대한 기 존 연구결과를 오프라인에서와 같은 개인적이 고 감정적인 상호작용이 일어나기 보다는 보다 정보에 입각해서 의사결정이 이루어지는 온라 인 경매라는 새로운 거래상황을 대상으로 그 일반화 가능성을 검증하며, 또한 기존의 차별적 정박효과 이외에도 판매자와 구매자의 용의가 격의 차이에 영향을 줄 수 있는 조절변수로서 제품 유형(product type)과 소비자가 가지고 있 는 목적 지향성 (goal orientation)의 효과에 대하 여 살펴보고자 한다. 소비자가 판매하거나 구매 하려는 제품이 실용적 제품(utilitarian product) 인 경우와 쾌락적 제품(hedonic product)인 경 우, 제품의 가치를 판단하는 기준 자체에 보다 주관적인 요소가 개입할 수 있는 여지의 정도 가 달라지게 되며, 판매자와 구매자가 동일 제 품에 대해서 느끼는 가치도 달라질 수 있음을 기존 연구(Dhar and Wertenbroch 2000)를 바 탕으로 추측해 볼 수 있다. 또한, 소비자가 추 구하는 목적이 향상 목적(promotion goal)인 경 우와 예방 목적(prevention goal)인 경우 소비 자의 지불용의가격과 판매용의가격의 차이가 어떻게 달라질 수 있는지 연구하고자 한다. 광 고 등의 커뮤니케이션에 의해 구매 및 판매상 황에서의 소비자들의 추구목적 자체가 영향을 받을 수 있으며, 기존 연구(Higgins 1997)를 바 탕으로 추구목적이 달라짐에 따라 판매 및 구 매로부터 발생할 수 있는 효용 및 금전적인 면 에서의 이득과 손실에 대하여 소비자들은 다르 
게 반응하여, 결국 판매희망가격과 구매희망가 격에서의 차이로 연결될 수 있게 되는 것이다.

\section{II. 이론적 배경 및 가설의 설정}

\section{1 구매 상황과 판매 상황의 소비자 제시가격 차이}

기존의 경제학적 관점에서 살펴보면 제품의 효용은 소비자들이 해당 제품을 판매할 때나 구매할 때나 모두 같기 때문에, 구매자의 지불 용의가격이나 판매자의 판매용의가격은 차이가 없어야 한다(Carmon and Ariely 2000). 그러나 기존의 소비자 연구에서 살펴보면, 소유효과 (endowment effect)나 위험회피(loss aversion) 성향으로 인하여 판매자와 구매자 간의 수용가 격에는 차이가 있다는 것이 밝혀졌다(Bar-Hillel and Neter 1996; Kahneman and Tversky 1979; Tversky and Kahneman 1991; Thaler 1980). 즉, 소유효과에 따르면, 어떤 제품을 소 유했다가 이를 상실하게 되는 경우에는 오히려 소유하지 않는 경우보다 그 제품의 가치를 더 욱 높게 지각하게 된다. 또한, 동일 제품에 대 해 판매자의 경우 그 제품이 판매되었을 경우 에는 직접적인 손실(loss)을 경험하게 되고, 구 매자의 경우에는 해당 제품을 구매하지 못하였 을 경우 달성하지 못한 이득(forgone gain)을 경험하게 된다. 따라서 위험회피성향에 따르면 판매자가 느끼는 상실감과 그에 따른 제품의 지각된 가치가 구매자가 느끼는 가치보다 더욱 커지기 때문에, 결국 이는 구매자가 평가하는
가격 보다 높은 판매용의가격(WTS)으로 연결 된다(Kahneman and Tversky 1979; Tversky and Kahneman 1991). 또한, Carmon and $\operatorname{Ariely}(2000)$ 의 연구를 살펴보면 소비자는 교환 시 무엇을 잃어버리는가에 초점을 두는 경향이 있다고 한다. 물건을 사는 사랍은 금전적인 측 면, 즉, 내가 얼마를 지불해야 되는가에 초점을 두고, 물건을 파는 사람은 물품적인 측면, 즉, 내가 소유하고 있는 물건을 포기하는 것에 초 점을 둔다는 것이다. 그러므로 구매자는 비숫한 제품의 시장 가격에 따라서 물건의 가격을 제 시하지만, 판매자는 소유하고 있는 물건의 가치 를 보다 높게 평가하기 때문에 주위의 시장 가 격에 상관없이 높은 가격을 받기를 원하는 것 이다. 이러한 소비자들의 심리는 인터넷 경매 싸이트에서 일반적으로 판매가격이 구매가격보 다 높은 이유를 설명해주는 논리적 근거가 된다.

따라서 이상에서 언급한 근거에 따르면 소비 자들이 한 제품을 판매할 때 제시하는 가격 (WTS)은 그 제품을 구매할 때 제시하는 가격 (WTP)에 비하여 높게 형성될 것이라는 다음 의 가설 1 을 설정하였다.

가설 1: 판매상황에서의 용의가격(WTS)은 구 매상황에서의 용의가격(WTP)에 비 해 높게 형성둴 것이다.

\section{2 상황에 따른 소비자 제시가격과 제품 유형 간의 상호작용}

그러나 이상에서 살펴본 판매자와 구매자의 수용가격의 차이는 대상제품의 특징에 의해 영 향을 받을 수 있다. 본 연구에서는 이러한 제품 
의 특징으로 실용적 제품(utilitarian product)과 쾌락적 제품(hedonic product)이라는 두 가지 제품유형의 조절적 영향에 대해 살펴보고자 한 다. 실용적 제품은 제품의 소비를 통하여 기능 적이고 실제적인 임무를 수행할 수 있고 기본 적인 욕구를 충족시키는데 도움을 줄 수 있는 제품을 말하며, 쾌락적 제품은 제품의 소비를 통해 즐거움, 아름다움 등의 감정적이고 감각 적인 경험을 얻을 수 있는 제품을 말한다 (Lecterc, Schmitt and Dube 1994). 이와 같이 제품 유형을 나눌 수 있는 것은 소비자들이 제 품을 소비하는 경우 서로 다른 동기와 선호체 계가 발생하기 때문이다. 우선 동기적 측면을 살펴보면, 소비자가 제품을 구매하는 동기는 실 용적 동기(utilitarian motive)와 쾌락적 동기 (hedonic motive)로 구분 될 수 있다. 실용적 동기는 제품을 소비함으로서 실용적인 효용을 얻으려고 하는 것이며, 쾌락적 동기는 제품 소 비에 의하여 즐거움을 얻고자 하는 것을 말한 다(이학식, 안광호, 하영원 2001). 또한, 소비자 들은 제품 선호 시 인지적 선호(should)와 감 정적 선호(wants)를 가지게 되는데, 실용적 가 치가 높은 속성 및 항목에 대해서는 인지적 선 호를 하며, 쾌락적 가치가 높은 속성 및 항목에 대해서는 감정적 선호를 주로 한다(Dhar and Wertenbroch 2000). 그러므로 제품 유형을 소 비자가 실용적인 효용을 얻기 위하여, 인지적 으로 선호하는 컴퓨터나 전자렌지 등과 같은 제품과 즐거움이나 홍분 등을 얻기 위하여. 감 정적으로 선호하는 명품이나 스포츠카 등과 같은 제품으로 구별가능 할 것이다(Dhar and Wertenbroch 2000; Hirschman and Holbrook 1982; Strahilevitz and Myers 1998).
이러한 제품 유형은 소비자들의 선택 과업에 영향을 준다. 즉, 소비자들이 쾌락적 속성을 보 다 많이 가진 제품과 실용적 속성을 보다 많이 가진 제품 중에서 선택을 할 때, 그 제품을 획 득하는 경우(획득선택)이냐 포기하는 경우(포 기선택)이냐에 따라서 선택에 차별적인 영향을 줄 수 있다는 것이다. Dhar and Wertenbroch (2000)의 연구에 따르면, 제품을 획득하는 경우 보다 포기하는 경우에 소비자들의 제품의 효용 에 대한 정교화(elaboration)가 쉽게 일어나며, 마찬가지로 실용적인 속성에 비해 쾌락적인 속 성인 경우 이러한 정교화가 더욱 잘 발생하기 때문에, 소비자들은 제품을 획득하는 경우보다 포기하는 경우 쾌락적 속성이 우세한 제품에 대한 선호가 상대적으로 증가하는 것으로 나타 났다. 즉, 제품을 흭득하는 경우에 비해 제품을 포기하는 경우 그 제품의 손실로 인해 느끼게 될 감정을 미리 상상(prefactual thinking)하기 가 쉽기 때문에 정교화(elaboration)가 보다 쉽게 일어날 수 있으며, 이러한 상상과 정교화는 그 제품의 상대적 매력도를 증가시킬 수 있는 쾌 락적 속성에서 보다 쉽게 일어난다. 쾌락적 속성 은 소비자의 감정을 자극할 수 있고 상상을 불 러일으킬 수 있다는 특징이 있으므로(MacInnis and Price 1987) 쾌락적 속성이 우세한 제품은 제품을 획득하는 경우보다는 포기하는 경우에 서 그 영향력을 증가시킬 수 있다는 것이다. 또 한 소비자들은 제품을 포기하는 경우에 쾌락적 속성을 가진 대안을 남겨둠으로써 손실로 인한 부정적 감정을 최소화하려고 노력 한다는 결과 도 있다(Strahilevitz and Loewenstein 1998). 반면, 소비자들은 제품을 흭득하는 경우에는 정 당한 이유(reason)와 설명(argument)을 찾으려 
는 경향이 있으며(Tversky and Griffin 1991), 이러한 정당한 이유와 설명은 실용적 속성에 대한 선호를 증가 시킨다(Bohm and Pfister 1996). 따라서 소비자들이 제품을 획득하는 경 우에는 정당한 이유와 설명을 쉽게 찾을 수 있 는 실용적 속성이 우세한 제품에 대한 선호가 증가하게 된다고 말할 수 있다.

이러한 기존 연구결과들을 본 연구와 관련하 여 본다면, 제품을 획득하는 경우는 거래 상황 에서 제품을 구매하려는 상황에 해당하며, 제품 을 포기하는 경우는 거래 상황에서 제품을 판 매하려는 상황에 해당한다. 따라서 소비자들이 제품을 구매하는 경우에는 자신의 선택에 대한 정당한 이유나 설명을 찾으려는 경향이 있기 때문에, 소비자가 제품의 가치에 대해 보다 쉽 게 정당성을 찾을 수 있는 실용적 제품이 쾌락 적 제품에 비해 구매자의 대상 제품에 대한 가 치판단 및 지불용의 가격을 보다 높게 만들 수 있을 것으로 예상할 수 있다. 결국 구매 시의 소비자들의 이러한 경향은 실용적 제품에 대해 쾌락적 제품 보다 높은 지불용의 가격을 제시 할 가능성이 높을 것이다. 반면, 소비자들이 제 품을 판매할 때는 제품 유형이 쾌락적일 경우 제품 판매에 따른 상실감을 보다 쉽게 상상하 고 정교화 시킬 수 있기 때문에 대상 제품의 가치를 더욱 높게 평가하게 되고, 결과적으로 실용적 제품에 비하여 보다 높은 판매용의 가 격으로 나타날 가능성이 높다. 예를 들어, 스포 츠카를 판매하려는 사람은 같은 기능의 다른 자동차를 판매하려는 사람에 비하여 스포츠카 의 외적인 아름다움 및 강력한 엔진 사운드 등 과 같은 쾌락적 속성에 대해 보다 높은 가치를 느끼계 되고, 따라서 보다 높은 판매가격을 제
시하려는 경향을 보일 수 있는 것이다. 이처럼 쾌락적인 제품의 경우에는 실용적인 제품의 경 우에 비해서 판매자는 보다 큰 상실감을 상상 하게 되고, 그에 따라 보다 제품에 보다 큰 가 치를 지각하게 되나, 실용적인 속성에 보다 민 감한 구매자는 쾌락적인 속성에 대한 충분한 가치를 인식하지 못하여 둘 간의 수용가격의 차이가 벌어질 것을 예상할 수 있다.

따라서 본 연구에서는 소비자들이 한 제품을 판매할 때 제시하는 가격(WTS)과 그 제품을 구매할 때 제시하는 가격(WTP) 차이는 그 제 품이 실용적 제품일 때 보다 뢔락적 제품일 때 더욱 크게 나타난다는 다음의 가설 2 를 설정하 였다.

가설 2: 판매상황과 구매상황에서의 용의가 격의 차이(가설 1)는 거래되는 제품 이 실용적 제품(utilitarian product)일 때 보다 쾌락적 제품(hedonic product) 일 때 더욱 크게 나타날 것이다.

\section{3 상황에 따른 소비자 제시가격과 목적 지향성 간의 상호작용}

한편, 경매와 같은 상황에서의 거래를 성사시 키는데 영향을 주는 주요 요소로는 구매자와 판매자의 제시가격과 거래되는 제품의 유형뿐 만 아니라 대상제품에 대한 광고 등의 설득적 메시지와 같은 상황적 변수나 거래 당사자들의 개인적 성향 역시 중요한 역할을 차지하고 있 다. 따라서 본 연구에서는 이러한 상황적 및 개 인적 요소를 목적지향성이라는 개념을 통하여 그 효과를 연구하고자 한다. 
사람들이 각자 자신들이 바라는 바(desired end states)를 달성하기 위한 동기유형은 향상 목적(promotion goal)과 예방 목적(prevention goal)으로 나누어 볼 수 있다. 향상 목적은 만 족스럽거나 바라던 결과 및 상태를 얻기 위해 현재의 상황을 향상시키려는 목표에 자신의 동 기적 초점을 맞추는 것을 의미하는 반면, 예방 목적은 불만족스럽거나 원치 않는 결과 및 상 태가 일어나는 것을 막기 위하여 현재의 상황 을 유지하려는 목표에 동기적 초점을 맞추는 것을 의미한다(Higgins 1997). 향상 목적을 가 지고 있는 사람들은 자신이 바라는 소원이나 비전 등과 같이 본인이 이루기를 희망하는 이상 들을 추구하며, 이득(gain)과 무이득(nongain) 의 상황에 민감하게 반응하고, 긍정적인 결과를 달성하는 것에 초점을 두고 있다. 반면에 예방 목적을 가지고 있는 사람들은 의무나 책임과 같은 당위적인 것을 추구하며, 손실(loss)과 무 손실(nonloss)의 상황에 민감하게 반응하고, 부 정적인 결과를 피하는 것에 초점을 두고 있다 (Higgins 1997, 1998). 따라서 향상 목적과 예 방 목적의 주요한 차이점은 긍정적인 결과 (positive outcomes)와 부정적인 결과(negative outcomes)에 각각 다른 민감도(sensitivity)를 가지고 있다는 것이다. 즉. 향상 목적을 가지고 있는 사람은 칭찬(praise), 성취(achievements), 이득(gains)과 같은 긍정적인 결과의 존재여부 에 매우 민감한 반면, 예방 목적을 가지고 있는 사랍은 비판(criticisms), 실패(failures), 손실 (losses)과 같은 부정적인 결과의 존재여부에 매우 민감하다(Higgins 1998). 예를 들어, 자기 발전을 위하여 자격증 시험을 보는 경우를 살 펴보면, 시험에 합격한다면 매우 기분이 좋아지
는 긍정적인 결과(이득)를 가져오고, 시험에 불 합격했을 경우 기분이 좋아질 수 있는 기회가 없어진 것으로(무이득) 볼 수 있다. 이와 같은 '이득-무이득'의 상황에 처할 경우, 예방 목적을 가지고 있는 사람은 이러한 상황에 대하여 민 감하게 반응하지 않지만, 향상 목적을 가지고 있는 사람의 경우에는 이러한 상황에 대하여 민감하게 반응하고, 가능한 모든 방식을 동원하 여 자격증이 본인에게 줄 수 있는 자부심이나 즐거움과 같은 긍정적인 결과를 얻고자 노력한 다. 하지만 취직을 위하여 이번에 반드시 합격 해야 되는 자격증 시험을 보는 경우를 살펴보 면, 시험에 합격한다면 취직을 하지 못하는 불 상사를 막을 수 있지만, 시험에 불합격한다면 미취업자로 지낼 수밖에 없다. 이러한 '손실-무 손실'의 상황에 처할 경우 앞서 말한 '이득-무 이득'의 상황과는 반대로 향상 목적을 가지고 있는 사람은 이러한 상황에 대해 민감하게 반 응하지 않지만, 예방 목적을 가지고 있는 사람 은 매우 민감하여 반응하여 시험에 떨어지지 않기 위하여 매우 열심히 공부하게 된다.

이와 같은 소비자의 향상 목적과 예방 목적의 효과를 연구하기 위해 여준상 외(2004)의 연구 에서는 검은콩 우유라는 제품을 실험대상으로 하 여 소비자들에게 사전적인 프라이밍(priming) 과업을 실시하였다. 즉, 향상 목적으로 프라이 밍 시킨 집단에게는 검은콩 우유의 체질개선, 성장촉진, 신진대사촉진, 에너지공급, 두뇌발달 의 효과와 같은 긍정적인 프레이밍의 광고 메 시지를 보여주었으며, 예방 목적으로 프라이밍 시킨 집단에게는 검은콩 우유의 항암효과, 노화 방지, 심장병 예방, 시력저하 예방의 효과와 같 은 부정적인 프레이밍의 광고 메시지를 보여줌 
으로써 소비자의 목적 지향성을 조작하였다.

이러한 현상을 소비자가 제품을 판매하는 상 황에서 살펴보면, 판매자는 만약 제품이 판매가 된다면 금전적인 측면에서의 이득(gain)과 해 당제품이 주었던 효용이라는 측면에서의 손실 (loss)이 발생하는 상황이 되지만, 만약 제품이 판매되지 않는다면 금전적인 측면에서의 무이 독(non-gain)과 제품의 효용 측면에서의 무손 실(non-loss)이 발생하는 상황이 된다. 반면, 소 비자가 제품을 구매하는 상황을 살펴보면, 구매 자는 만약 제품을 구매하게 된다면 해당제품이 주는 효용 측면에서의 이득(gain)과 금전적인 측면에서의 손실(loss)이 발생하는 상황이 되지 만, 만약 제품을 구매하지 않게 된다면 제품의 효용 측면에서는 무이득(non-gain)이 되고 금 전적인 측면에서는 무손실(non-loss)이 되는 상 황이 발생하게 된다.

따라서 우선 소비자가 향상 목적을 가지고 있 는 경우를 먼저 살펴보면, 소비자가 물건을 판 매하는 상황에서는 물건을 판매함으로써 발생 하는 제품 측면에서의 효용의 손실 보다는 금 전적인 이득에 더욱 민감하게 반응하게 되어, 이를 실현하기 위해 판매용의가격을 보다 낮추 려는 의향이 생길 수 있을 것이다. 반면, 물건 을 구매하는 상황에서는 구매함으로써 발생하 는 금전적인 손실 보다는 제품효용 측면에서의 이득에 더욱 민감하게 반응하여, 이를 실현하고 자 지불용의가격을 보다 높이고자 하는 의향이 생길 수 있을 것이다. 한편, 소비자가 예방 목 적을 가지고 있는 경우를 생각해 보면, 소비자 가 물건을 판매하는 상황에서는 금전적인 이득 보다는 물건을 판매함으로써 생기는 제품효용 면에서의 손실에 민감하게 반응하여 판매용의
가격이 보다 높아질 수 있을 것이고, 물건을 구 매하는 상황에서는 구매함으로써 생기는 금전 적인 손실에 민감하게 반응하여 지불용의가격 이 보다 낮아질 수 있올 것이다. 따라서 긍정적 메시지를 통하여 소비자가 향상 목적을 가지도 록 조작하는 경우, 부정적 메시지를 통하여 소 비자가 예방 목적을 가지도록 조작하는 경우보 다 지불용의가격과 판매용의가격의 차이가 더 줄어들어 가격협상이 쉬워질 것이다.

지금까지의 논의를 바탕으로 본 연구에서는 소비자들이 한 제품을 판매할 때 제시하는 가 격(WTS) 과 그 제품을 구매할 때 제시하는 가 격(WTP)의 차이는 소비자들이 향상 목적을 가지고 있을 때 보다 예방 목적을 가지고 있을 때 더욱 두드러지게 나타난다는 다음의 가설 3 을 설정하였다.

가설 3: 판매상황과 구매상황에서의 용의가 격의 차이(가설 1 )는 소비자가 향상 목적(promotion goal)을 가지고 있올 때 보다 예방 목적(prevention goal) 을 가지고 있을 때 더욱 크게 나타 날 것이다.

\section{4 연구모형}

이상에서는 소비자들이 제품을 판매하는 경 우와 제품을 구매하는 경우 동일 제품에 대한 수용가격이 어떻게 달라지는지, 그리고 거래되 는 제품의 유형과 소비자들이 가지고 있는 목 적지향성이 이러한 판매자와 구매자의 수용가 격의 차이에 어떻게 조절변수로서 작용을 하는 지에 대한 가설과 근거를 제시하였다. 따라서 
〈그림 1〉 연구모형

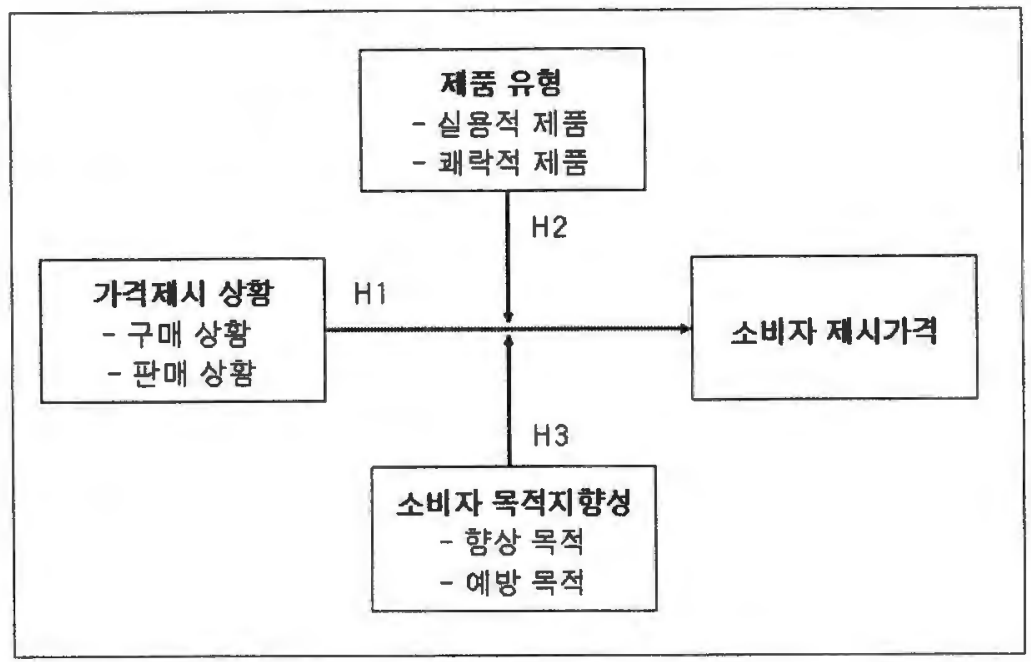

본 연구의 개념적 모형을 도식화하면 〈그림 1〉 과 같다.

\section{III. 연구방법}

\section{1 실험설계}

본 연구에서는 앞서 언급한 가설들을 검증하 기 위하여 $2 \times 2 \times 2$ 집단 간 실험설계(between subjects design)를 적용하였다. 구체적으로, 세 가지 요인을 살펴보면 (1)가격제시 상황(구매 상황/판매 상황), (2)제품 유형(실용적 제품/뢔 락적 제품), (3)소비자 목적 지향성(향상 목적/ 예방 목적)이다. 따라서 본 연구에서는 8가지의 시나리오가 만들어졌으며, 그에 앞서 실험제품 선정 및 소비자의 목적 지향성의 실험조작을 위해 2번의 예비조사가 행해졌다.
3.2 사전조사

우선 연구대상이 될 실용적 제품과 쾌락적 제 품을 선정하기 위하여 1 차 사전조사를 실시하 였다. 선정기준은 (1)각각 소비자들에게 실용적 제품과 쾌락적 제품으로 인지되고 있는 제품이 면서, (2)소비자들이 각각의 제품에 대해 어느 정도 이상의 그리고 동시에 비슷한 수준의 관 여도, 선호도, 친숙도를 가지고 있으며, 또한 제 품에 대한 지식수준 및 가격수준 역시 비슷하 게 인지되고 있는 제품이어야 한다는 것이었다. 이를 위해 5 명의 대학원생들과의 인터뷰를 통 하여 실험대상으로 적합하다고 간주되는 제품 군 리스트를 파악한 후, 대학생 30명을 대상으 로 총 9개의 제품군(전자사전, MP3, 선글라스, 지갑, 디지털카메라. 핸드폰, 노트북, 향수, 손목 시계)에 대한 설문조사를 실시하였다. 이 때 실 용적 제품과 쾌락적 제품은 Hirschman and Holbrook(1982) 과 Strahilevits and Myers(1998) 의 정의(〈그림 2〉참고)를 바탕으로 하여 Loclerc 
et al.(1994)의 연구에서 사용된 7점 척도문항 $(1=$ 실용적이다, $7=$ 쾌락적이다)을 사용하였으 며, 관여도 $(1=$ 전혀 관심 없다, $7=$ 매우 관심 많다), 선호도 $(1=$ 매우 싫어한다, $7=$ 매우 좋아 한다), 친숙도 $(1=$ 전혀 친숙하지 않다, $7=$ 매우 친숙하다) 및 지식수준( $1=$ 전혀 모른다. $7=$ 매 우 잘 안다)도 7점 척도를 사용하였다. 또한 제 품별 준거가격을 물어봄으로써 가격수준을 파 악하였다. 선정기준에 적당한 제품군을 알아본 결과 실용적 제품에는 '전자사전(M=1.47)', 캐 락적 제품에는 '선글라스 $(\mathrm{M}=5.80)$ '가 선정되었 고 $(\mathrm{t}(29)=-21.708, \mathrm{p}<01)$, 두 제품군은 비슷한 수준의 관여도 $(\mathrm{M}=4.67$ vs. $\mathrm{M}=4.33 ; \mathrm{t}(29)=$ $1.056, p>0.1)$, 선호도( $M=4.90$ vs. $M=4.50 ; t$ $(29)=1.484, \mathrm{p}>0.1)$, 친숙도 $(\mathrm{M}=5.73$ vs. $\mathrm{M}=$ 5.50; $t(29)=0.815, p>0.1)$, 지식수준 $(M=3.80$ vs. $\mathrm{M}=3.77 ; \mathrm{t}(29)=0.085, \mathrm{p}>0.1)$ 및 가격수준 $(\mathrm{M}=$ 162,667 원(최저가: 100,000 원, 최고가: 250,000 원) vs. $\mathrm{M}=173,333$ 원(최저가: 100,000 원, 최고 가: 250.000 원); $t(29)=-1.069, \mathrm{p}>0.1)$ 을 갖는 것으로 나타났다.

다음으로 소비자의 목적 지향성을 조작하기 위해 2 차 사전조사가 실시되었다. 2 차 사전조사
에서 소비자의 목적 지향성에 대한 조작은 문 장기술과업(이에 대한 구체적인 내용은 실험자 극 참고)을 통해 실시하였으며(Lockwood, Jordan and Kunda 2002), 이에 대한 측정은 다음과 같 은 세 문항의 양극단 7점 척도(bi-polar scale) 를 사용하였다(나준희 2004: 1=나는 제품을 구매할 때 제품의 좋은 점을 파악하는데 관심 을 갖는다, $7=$ 나는 제품을 구매할 때 제품의 나쁜 점을 파악하는 데 관심을 갖는다; $1=$ 나 는 제품을 구매할 때 제품의 좋은 점이 있으면 구매한다. $7=$ 나는 제품을 구매할 때 제품의 나 쁜 점이 있으면 구매하지 않는다: $1=$ 내가 구 매하는 제품은 긍정적인 면이 있어야 한다, $7=$ 내가 구매하는 제품은 부정적인 면이 없어야 한다). 여기서 4점을 기준으로 1점에 가까울수 록 향상 목적에 가까우며, 7점에 가까울수록 예 방 목적에 가깝다고 판단하여, 30 명의 대학생을 대상으로 이러한 예비조사를 실시한 결과, 위의 세 문항의 평균값을 하나의 단일변수로 취급하 여 비교해 보니 향상 목적으로 프라이밍 된 집 단 $(\mathrm{M}=1.93)$ 과 예방 목적으로 프라이밍 된 집 단 $(\mathrm{M}=4.53)$ 의 평균의 차이가 통계적으로 유의 하게 나타나 $(\mathrm{t}(28)=10.406, \mathrm{p}<.01)$ 목적 지향성

\section{〈그림 2〉 실용적 제품과 쾌락적 제품의 파악을 위한 설문 시나리오의 예}

실용적 졔품이란, 실용적이고 기능적이며, 실무적인 과제수행에 수단이 되는 기본적인 속성이 강한 제 품을 말한다. 실용적 속성의 가치(value)는 인지적이고 기능적이며, 필수적인 속성의 특징을 나타내며, 선호해야만 할 것 같은(should preference)속성을 의미한다.

켸락적 졔품이란, 쾌락적이고 감각적인 즐거움이나 기뽐, 또는 재미를 느끼게 하며 반드시 필수적이지 않은 사치스러운 속성이 강한 제품을 말한다. 쾌락적 속성의 가치(value)는 감각적인 경험이나 기쁨, 재 미 등을 나타내는 특징을 가지고 있으며, 선호하고 싶은(want preference)속성을 의미한다.

선글라스는 실용적 제품입니까, 쾌락적 제품입니까? (정도에 따라 하나 선택하세요) 실용적 제품 1----2----3----4----5----6-----7 쾌락적 제품 
에 대한 실험조작이 성공적으로 되었음을 확인 하였다.

\section{3 본 조사}

\subsection{1 실험 참가자}

실험 참가자들을 위에서 언급한 3 가지 실험 변수 즉, (1)가격제시 상황(구매 상황/판매 상 황), (2)제품 유형(실용적 제품/뢔락적 제품), (3)소비자 목적 지향성(향상 목적/예방 목적) 의 $2 \times 2 \times 2$ 집단 간 실험설계(between subjects design)에 따른 전체 8 가지의 실험상황에 무작 위로 할당하였다. 서울시내에 소재하고 있는 대 학교에서 264 명의 학부생들이 수업의 일부분으 로 실험에 참가하였으며, 회수된 설문지 중 불 성실하게 응답한 10 부를 제외한 254 부가 연구 에 사용되었다. 본 조사에서는 사전조사에 참여 한 학생들은 배재하였으며, 각 실험집단의 크기 는 〈표 1〉에서 제시된 바와 같이 28명에서 33 명이었다.

\subsection{2 실험 자극}

우선 소비자들의 목적 지향성을 프라이밍 시
키기 위하여 문장기술과업(description task)을 실시하였다(Lockwood, Jordan and Kunda 2002). 문장기술과업은 2 개의 내용에 대해 시행되었다. 하나는 일상적인 내용이며, 다른 하나는 제품구 매와 관련된 내용이었다. 향상 목적과 관련한 일상적인 내용에 대한 문장기술과업은 이루고 싶은 소망이나 성취하고자 하는 줗은 것을 적 고 이를 이루기 위해서는 어떻게 해야 하는지 를 적게 하였으며, 제품구매와 관련된 내용에 대한 문장기술과업은 최근에 자신이 구매하고 자 하는 제품을 기술하고 이를 통해 얻고자 하 는 소망을 적게 하였다. 반면에 예방동기와 관 련한 일상적인 내용에 대한 문장기술과업은 좋 지 못한 일이어서 일어나지 않았으면 하는 것 을 적고 이를 피하기 위해서는 어떻게 해야 하 는지를 적게 하였다. 또한 제품구매와 관련된 내용에 대한 문장기술과업은 최근에 자신이 구 매하고자 하는 제품을 기술하고 이를 통해 부 정적인 것을 피하고자 하는 소망을 기술하게 하였다.

문장기술과업을 완료한 후, 피 실험자들에게 구매상황 및 판매상황을 제시하기 위하여, 각각 6 종류의 '전자사전'(가격대: 100,000 원 250,000 원) 과 6 종류의 '선글라스'(가격대: 100,000 원 250,000 원)에 관한 특징과 가격을 비교해볼 수

〈표 1〉실험설계와 각 실험집단의 크기

\begin{tabular}{|c|c|c|c|c|}
\cline { 2 - 5 } \multicolumn{1}{c|}{} & \multicolumn{2}{c|}{ 실용적 제품 } & \multicolumn{2}{c|}{ 홰락적 제품 } \\
\cline { 2 - 5 } \multicolumn{1}{c|}{} & 향상 목적 & 예방 목적 & 향상 목적 & 예방 목적 \\
\hline \multirow{2}{*}{ 구매 상황 } & 전자사전 & 전자사전 & 선글라스 & 선글라스 \\
& $(\mathrm{N}=33)$ & $(\mathrm{N}=32)$ & $(\mathrm{N}=33)$ & $(\mathrm{N}=32)$ \\
\hline \multirow{2}{*}{ 판매 상황 } & 전자사전 & 전자사전 & 선글라스 & 선글라스 \\
& $(\mathrm{N}=33)$ & $(\mathrm{N}=31)$ & $(\mathrm{N}=32)$ & $(\mathrm{N}=28)$ \\
\hline
\end{tabular}


있는 가상의 시나리오를 제시하였다. 피 실험자 들은 그 시나리오를 통해 제품에 대한 평가와 제품 간 비교를 한 후, 구매상황과 판매상황이 라는 가정 하에 그 다음 페이지에서 보이는 전 자사전과 선글라스에 관한 가격을 결정하였다. 이러한 구매상황 및 판매상황에서 제시된 전자 사전과 선글라스의 특징은 실제 옥션에서 거래 되고 있는 동일한 가격대의 제품을 참고로 하 여 작성되었다(부록 참고).

\subsection{3 종속변수 및 실험변수의 축정}

종속 변수인 소비자들이 제시하는 가격은 Simonson and Drolet(2004)의 연구에서 사용한 방법을 바탕으로 구매상황 시에는 최대 지불용 의가격(maximum willing-to-pay price)을 적게 하였고, 판매상황 시에는 최소 판매용의가격 (minimum willing-to-sell price)을 적게 하였다. 즉, 최대 지불용의가격은 “위의 제품을 옥션에 서 구매한다면, 최대 얼마의 가격을 제시하시겠 습니까?”, 최소 판매용의가격은 “위의 제품을 옥션에서 판매한다면, 최소 얼마의 가격을 제시 하시겠습니까?"라는 질문을 통하여 측정하였다. 종속변수의 측정과 함께 실험조작의 성공여부 를 파악하기 위하여 앞서 실시된 소비자의 목 적지향성 프라이밍을 사전조사에서 사용했던 3 가지 문항 $(1=$ 나는 제품을 구매할 때 제품의 좋은 점을 파악하는데 관심을 갖는다. $7=$ 나는 제품을 구매할 때 제품의 나뺀 점을 파악하는 데 관심을 갖는다: $1=$ 나는 제품을 구매할 때 제품의 줗은 점이 있으면 구매한다. $7=$ 나는 제 품을 구매할 때 제품의 나뽄 점이 있으면 구매 하지 않는다: $1=$ 내가 구매하는 제품은 긍정적
인 면이 있어야 한다, $7=$ 내가 구매하는 제품은 부정적인 면이 없어야 한다)을 통하여 7점 척 도로 측정하였고, 제품 유형에 대한 조작확인은 Leclerc et al.(1994)에서 사용된 7점 척도 문항 ( $1=$ 실용적이다, $7=$ 쾌라적이다)을 사용하였다. 한편 응답자들의 대상 제품에 대한 선호도, 지 각된 준거가격범위 및 지식에 대한 차이로 인해 발생할 수 있는 흔동효과(confounding effect) 의 가능성을 배제하기 위하여, 대상 제품에 대 한 응답자들의 선호도, 준거가격 수준과 범위, 지식정도 및 관여도를 7점 척도로 측정하였다.

\section{IV. 자료분석 및 가설검증}

\section{1 실험조작의 점검}

본 연구에 대한 실험을 실행한 결과. 예비조 사와 마찬가지로 전자사전과 선글라스에 대해 서 피 실험자가 각각 실용적 제품과 쾌락적 제 품으로 인식하였으며, 통계적으로 유의한 차이를 보였다( $\mathrm{M}=1.63$ vs, $\mathrm{M}=5.26, \mathrm{t}(252)=35.229$, $\mathrm{p}<.01)$. 또한 소비자들이 향상 목적 및 예방 목 적으로 프라이밍 되었는지 알아보기 위한 조작 은 복수의 측정문항을 사용하였기 때문에 문항 들 간의 내적 타당성을 살펴보았다. 그 결과 Cronbach' $a$ 계수가 0.93으로 높게 나와 이들의 평균을 구하여 단일변수로 측정하였다. 그 결 과, 향상 목적인 경우 $(\mathrm{M}=2.69)$ 와 예방 목적 $(\mathrm{M}=4.60)$ 인 경우 통계적으로 유의한 차이를 보였다(t(252) $=10.785, \mathrm{p}<01)$. 따라서〈표 2〉 에 제시된 바와 같이 본 연구의 실헙변수인 제 
품 유형과 소비자 목적지향성에 대한 실험조작 이 성공적으로 되었음을 확인하였다. 한편, 가 능한 혼동효과를 배제하기 위하여 측정된 두 제품에 대한 가격수준 $(\mathrm{t}(252)=1.12, \mathrm{p}>0.1)$, 지 각된 상한가격과 하한가격의 차이를 변수로 하 여 분석한 준거가격범위 $(\mathrm{t}(252)=0.08, \mathrm{p}>0.1)$ 등에 있어서도 제품유형 간 유의한 차이를 보 이지 않았으며, 선호도(t(252)=1.10, p>0.1), 지식수준 $(\mathrm{t}(252)=0.48, \mathrm{p}>0.1)$, 관여도 $(\mathrm{t}(252)$ $=0.02, \mathrm{p}>0.1)$, 친숙도 $(\mathrm{t}(252)=0.93, \mathrm{p}>0.1)$ 등 에서도 집단 간 유의한 차이를 보이지 않는 것 으로 나타났다.

\section{2 가설 검증}

\section{2 .1 가설 1 의 검증}

가설 1 에서는 소비자들이 제품을 판매할 때의 용의가격(WTS)은 그 제품을 구매할 때의 용 의가격(WTP)에 비하여 높을 것으로 예상하였 다. 가설 1 의 예상대로 가격 제시상황에 따른 주효과(main effect) 가 통계적으로 유의하게 나 타났다 $(\mathrm{F}(1,246)=16.586, \mathrm{p}<.01$ : 〈표 4〉참고). 〈표 3〉에 제시된 바와 같이 피 실험자들은 제 품을 구매하는 경우 $(\mathrm{M}=201.262)$ 보다 판매하는

〈표 2〉 실험조작에 대한 피험자 반응

\begin{tabular}{|l|c|c|}
\cline { 2 - 3 } \multicolumn{1}{c|}{} & 평균(표준편차) & t-value \\
\hline 제품 유형: & & \\
실용적 제품인 경우 & $1.63(0.75)$ & $35.229^{* * *}$ \\
쾌락적 제품인 경우 & $5.26(0.89)$ & \\
\hline 소비자의 목적 지향성: & & $10.785^{* * *}$ \\
향상 목적인 경우 & $2.69(0.98)$ & \\
예방 목적인 경우 & $4.60(1.75)$ & \\
\hline
\end{tabular}

주1) 7점 척도로 측정함

주2) ${ }^{*} \mathrm{p}<1,{ }^{* *} \mathrm{p}<.05,{ }^{* * *} \mathrm{p}<.01$

〈표 3〉 실험집단별 소비자 제시가격의 평균값과 표준편차

\begin{tabular}{|c|c|c|c|c|c|}
\hline & \multicolumn{2}{|c|}{ 실용적 제품 } & \multicolumn{2}{|c|}{ 쾌락적 제품 } & \\
\hline & 향상 목적 & 예방 목적 & 향상 목적 & 예방 목적 & \\
\hline 구매 상황 & $\begin{array}{l}231.818 \\
(56.22)\end{array}$ & $\begin{array}{l}216.531 \\
(54.21) \\
\end{array}$ & $\begin{array}{l}189.242 \\
(66.05) \\
\end{array}$ & $\begin{array}{l}166.875 \\
(85.85) \\
\end{array}$ & $\begin{array}{l}201.262 \\
(70.50) \\
\end{array}$ \\
\hline \multirow[t]{3}{*}{ 판매 상황 } & $\begin{array}{l}224.667 \\
(49.37) \\
\end{array}$ & $\begin{array}{l}235.258 \\
(59.91)\end{array}$ & $\begin{array}{l}227.406 \\
(82.99) \\
\end{array}$ & $\begin{array}{r}262.143 \\
(100.92) \\
\end{array}$ & $\begin{array}{l}236.484 \\
(75.43) \\
\end{array}$ \\
\hline & $\begin{array}{l}228.242 \\
(52.62) \\
\end{array}$ & $\begin{array}{l}225.746 \\
(57.41)\end{array}$ & $\begin{array}{l}208.030 \\
(76.73) \\
\end{array}$ & $\begin{array}{r}211.333 \\
(104.07) \\
\end{array}$ & \\
\hline & \multicolumn{2}{|c|}{$227.023(54.81)$} & \multicolumn{2}{|c|}{$209.616(90.52)$} & \\
\hline
\end{tabular}

주) 단위는 천원이며, 괄호 안의 숫자는 표준편차임. 
경우 $(M=236.484)$ 더욱 높은 용의가격을 제시 한 것으로 나타났다. 따라서 가설 1 은 지지되었다.

\section{2 .2 가설 2 의 검증}

가설 2에서는 가설 1 에서 나타난 소비자들이 제품을 판매할 때의 용의가격(WTS)과 제품을 구매할 때의 용의가격(WTP)의 차이는 거래되 는 제품이 실용적 제품(utilitarian product)일 때 보다 쾌락적 제품(hedonic product)일 때 더 욱 크게 나타날 것으로 예상하였다. 가설 2의 예상대로 가격제시 상황과 제품 유형과의 상호 작용효과(interaction effect)가 유의하게 나타났 다 $(\mathrm{F}(1,246)=11.713, \mathrm{p}<.01$ : 〈표 4〉 참고). 〈그 림 3〉에서 보는 바와 같이 실용적 제품의 경우 판매 상황에서의 용의가격 $(\mathrm{M}=229.962)$ 과 구
매 상황에서의 용의가격 $(\mathrm{M}=224.175)$ 의 차이 는 5,787 원이지만, 쾌락적 제품의 경우에는 판매 상황에서의 용의가격 $(\mathrm{M}=244.775)$ 과 구매 상황 에서의 용의가격 $(\mathrm{M}=178.059)$ 의 차이는 66,716 원으로 나타났다. 따라서 소비자들이 제품을 판 매할 때의 용의가격과 제품을 구매할 때의 용 의가격의 차이는 실용적 제품일 때 보다 쾌락 적 제품일 때 더욱 크게 나타났다. 따라서 가설 2는 지지되었으며, 제품 유형에 따라 구매자와 판매자의 용의가격의 차이가 달라진다는 것을 확인할 수 있었다.

\section{2 .3 가설 3 의 검증}

가설 3 에서는 가설 1 에서 나타난 소비자들이 제품을 판매할 때의 용의가격(WTS)과 제품을

\section{〈표 4〉 가설검증을 위한 분산분석(ANOVA)}

종속변수: 소비자 제시가격(단위: 천원)

\begin{tabular}{|c|c|c|c|c|}
\hline 원천(source) & 평 균 & d.f. & MS & $\mathrm{F}$-value \\
\hline $\begin{array}{l}\text { A. 가격제시 상황: } \\
\text { 구매 상황인 경우 } \\
\text { 판매 상황인 경우 }\end{array}$ & $\begin{array}{l}201.262 \\
236.484\end{array}$ & 1 & 83232.019 & $16.586^{* * *}$ \\
\hline $\begin{array}{l}\text { B. 제품 유형: } \\
\text { 실용적 제품인 경우 } \\
\text { 쾌락적 제품인 경우 }\end{array}$ & $\begin{array}{l}227.023 \\
209.616\end{array}$ & 1 & 15515.549 & $3.092^{*}$ \\
\hline $\begin{array}{l}\text { C. 소비자 목적 지향성: } \\
\text { 향상 목적인 경우 } \\
\text { 예방 목적인 경우 }\end{array}$ & $\begin{array}{l}218.214 \\
218.715\end{array}$ & 1 & 233.086 & 0.046 \\
\hline $\begin{array}{l}A \times B \\
A \times C \\
B \times C \\
\end{array}$ & & $\begin{array}{l}1 \\
1 \\
1 \\
\end{array}$ & $\begin{array}{r}58777.237 \\
27257.384 \\
1152.685 \\
\end{array}$ & $\begin{array}{c}11.713^{* * *} \\
5.432^{* *} \\
0.632 \\
\end{array}$ \\
\hline$A \times B \times C$ & & 1 & 3859.553 & 0.381 \\
\hline Error & & 246 & 5018.312 & \\
\hline
\end{tabular}

주) ${ }^{*} \mathrm{p}<.1,{ }^{* *} \mathrm{p}<.05,{ }^{* * *} \mathrm{p}<.01$ 
구매할 때의 용의가격(WTP)의 차이는 소비자 가 향상 목적(promotion goal)을 가지고 있을 때보다 예방 목적(prevention goal)을 가지고 있을 때 더욱 크게 나타날 것으로 예상하였다. 가설 3의 예상대로 소비자 목적 지향성의 조절적
효과에 따른 상호작용효과(interaction effect)가 유의하게 나타났다 $(F(1,246)=5.432, p<.05$ : 〈표 4) 참고). 〈그림 4>에서 보는 바와 같이 향상 목적을 가지고 있는 피 실험자들의 경우 판매 상황에서의 용의가격 $(\mathrm{M}=226.036)$ 과 구매 상황

〈그림 3〉 상황에 따른 소비자 제시가격과 제품 유형간의 상호작용효과

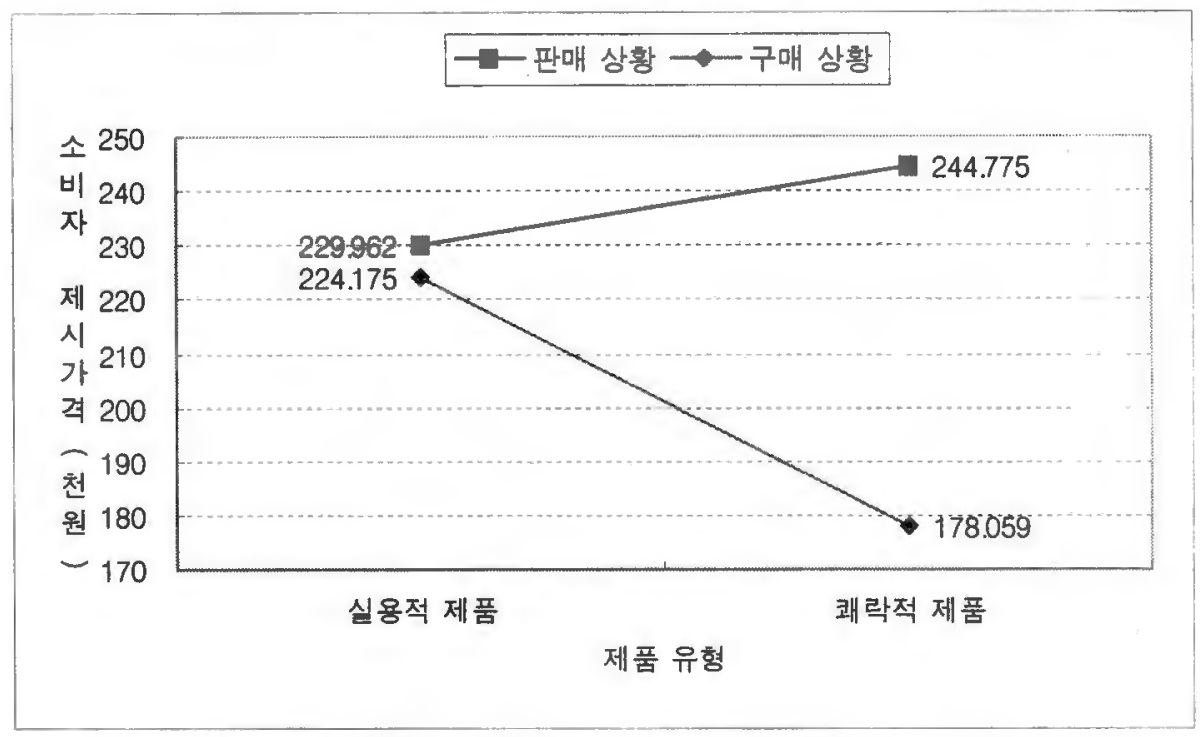

〈그림 4〉 상황에 따른 소비자 제시가격과 소비자 목적 지항성의 상호작용효과

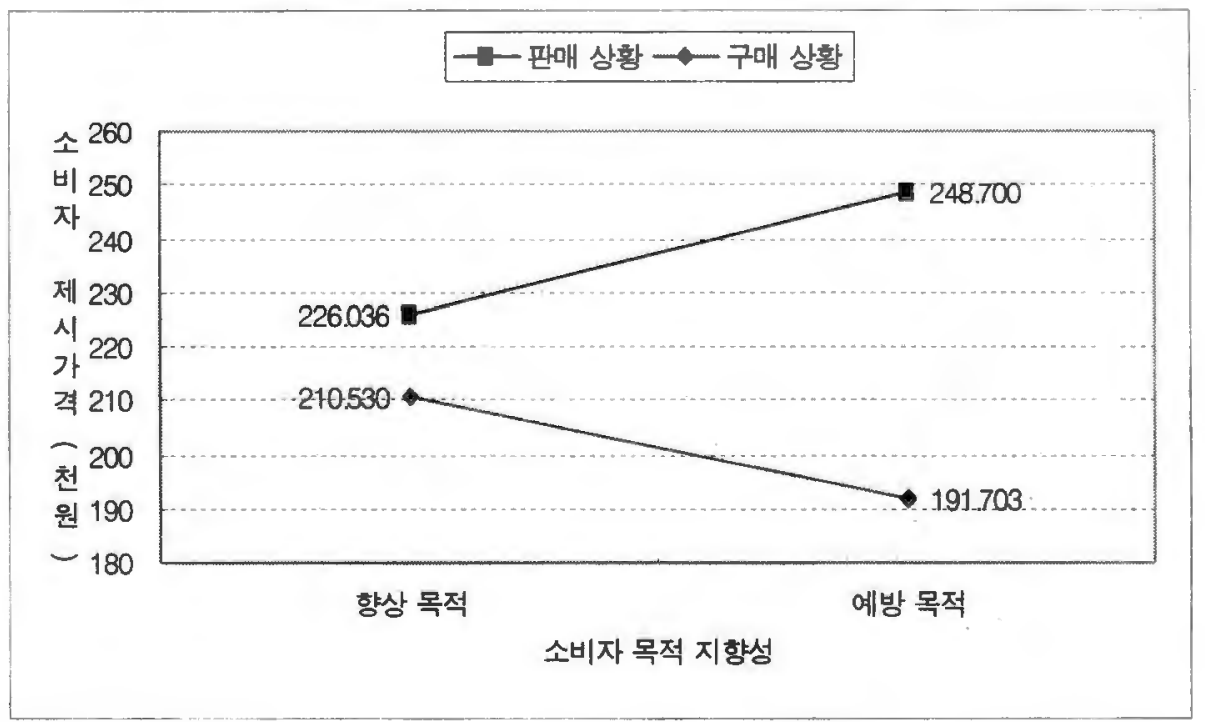


에서의 용의가격 $(\mathrm{M}=210.530)$ 의 차이는 15,506 원이지만, 예방 목적을 가지고 있는 피 실험자 들의 경우에는 판매 상황에서의 용의가격 $(\mathrm{M}=$ $248.700)$ 과 구매 상황에서의 용의가격( $M=191.703)$ 의 차이는 56,997 원으로 나타났다. 따라서 소비 자들이 제품을 판매할 때의 용의가격과 제품을 구매할 때의 용의가격의 차이는 소비자들이 향 상 목적을 가지고 있을 경우보다 예방 목적을 가지고 있을 경우 더욱 크게 나타났다. 따라서 가설 3 은 지지되었으며, 소비자의 목적 지향성 에 따라 판매자와 구매자의 용의가격의 차이가 영향을 받는다는 것을 확인할 수 있었다.

\section{V. 결론 및 논의}

\section{1 연구결과 및 시사점}

본 연구는 우선 기존의 연구에서 측정했던 소 비자들의 지불용의가격(WTP) 및 판매용의가 격(WTS)을 최근에 많은 소비자들이 경험하고 있는 새로운 유통경로인 온라인 경매라는 상황 을 통하여 그 일반화 가능성을 검증해 보았으 며, 이에 영향을 주는 조절변수들을 파악하여 그 효과를 살펴봄으로써 기존 연구의 영역을 확대하고자 하였다. 본 연구를 통하여 소비자들 은 같은 제품이라도 구매하는 상황일 때와 판 매하는 상황일 때 수용하는 가격이 다르게 나 타났으나, 이러한 상황에 따른 가격의 차이는 제품 유형과 소비자의 목적 지향성에 의해서 조절된다는 사실을 발견하였다. 이러한 연구결 과에 따른 본 연구의 이론적 및 실무적 시사점
은 다음과 같다.

첫째, 소비자들이 제품을 판매할 때의 용의가 격(WTS)은 그 제품을 구매할 때의 용의가격 (WTP)에 비해 높다는 기존 연구결과(Simonson and Drolet 2004)를 온라인 경매라는 새로운 거 래상황에서도 일반화할 수 있었다. 이러한 차이 는 판매자의 소유효과(endowment effect)와 손 실회피(loss aversion) 성향에 기인하는 것으로, 따라서 경매담당자의 입장에서 거래를 보다 활 성화시키기 위해서는 제품을 판매하는 상황의 소비자들에게는 제품을 판매함으로써 얻게 되 는 금전적 보상이나, 혹은 온라인 경매 상에서 의 부가적인 혜택(예: 거래 성립에 따른 마일 리지 혜택 등)을 강조하는 방안을 생각해 볼 수 있을 것이다.

둘째, 제품 유형에 따라서 소비자의 지불용의 가격(WTP)과 판매용의가격(WTS)의 차이가 달라진다는 것을 알았다. 특히 쾌락적 제품인 경우, 지불용의가격은 낮고 판매용의가격은 높 기 때문에 가격 협상이 더욱 어려워지는 것으 로 나타넜다. 본 연구의 결과는 실용적 제품의 경우에는 판매상황이나 구매상황에서 제품의 효용을 쉽게 정교화 할 수 있으므로 제시가격 의 차이가 유의적이지 않을 수 있음을 보여 준 다. 그러나 쾌락적 제품의 경우에는 경험적 성 격으로 인해 구매자 보다 판매자가 자연스럽게 그 가치를 정교화 할 가능성이 높으므로 판매 제시가격이 구입제시가격 보다 유의적으로 높 을 수 있다. 결국 실용적 가치와 쾌락적 가치의 합으로서의 제품의 총 가치를 판단하는데 있어 서 판매자는 '평균적인 실용적 가치와 높은 캐 락적 가치의 합으로 판단하는 반면, 구매자는 '평균적인 실용적 가치와 낮은 쾌락적 가치'의 
합으로 판단하기 때문이라고 해석할 수 있다. 현재 소비자들은 '선글라스'와 같은 쾌락적 제 품을 판매하거나 구매할 때 '자외선 차단 기능' 과 같은 실용적 속성을 같이 강조하는 경향이 있으며, '전자사전'과 같은 실용적 제품을 판매 하거나 구매할 때도 '컬러' 혹은 '디자인'과 같 은 쾌락적 속성을 같이 강조하는 경향이 점점 강해지고 있다. 따라서 쾌락적 제품과 실용적 제품의 경계기준의 점점 모호해지는 현재의 상 황에서 마케팅 실무자들은 쾌락적 속성이 강한 제품이나 서비스를 판매할 때, 실용적인 속성을 첨가하고 이와 같은 속성을 광고 등을 통해 강 조, 부각시키거나, 연구결과에서 보듯이 구매자 들이 가치를 충분히 지각하지 못하는 쾌락적 속성들의 가치를 보다 쉽게 정교화시킬 수 있 도록 커뮤니케이션 해 줌으로써 구매자의 지불 용의가격을 높게 만들 수 있을 뿐만 아니라, 온 라인 경매 상에서의 거래를 활발히 만들 수 있 을 것이다.

셋째, 소비자의 목적 지향성에 따라 지불용의 가격(WTP)과 판매용의가격(WTS)의 차이가 달라진다는 것을 알 수 있었다. 특히 소비자가 예방 목적을 가지고 있을 경우, 지불용의가격은 낮고 판매용의가격은 높기 때문에 가격 협상이 더욱 어려워지는 것으로 나타났다. 따라서 온라 인 경매 상에서 제품을 판매하는 소비자들이 제품 판매를 통해 얻게 되는 이득(예: 금전적 인 보상, 부가적인 혜택 등)을 인식하는 향상 목적을 가지도록 해야 활발한 거래를 만들 수 있을 것이다. 구체적인 방법으로는 여준상 외 (2004)의 연구에서 나타난 바와 같은 향상 목 적의 광고 메시지를 사용하는 것이 하나의 방 법이 될 수 있을 것이다.

\section{2 연구의 한계점 및 향후 연구방향}

그러나 본 연구는 여러 한계점을 가지고 있 다. 본 연구의 한계점 및 향후 연구방향을 생각 해 보면 다음과 같다.

첫째, 소비자가 제품 혹은 서비스를 구매하거 나 판매하는 상황에서 가격을 결정할 때는 여 러 가지 요소가 영향을 미칠 수 있지만, 본 연 구에서는 설문상의 제약 때문에 모든 요소를 고려하지 못하였다. 예를 들어, 설문지 상의 시 나리오에는 선글라스와 전자사전 각각 6 가지의 경쟁 제품을 보여주었다. 그러나 실제로 온라인 에서 구매자나 판매자가 가격 결정을 내릴 때 는 그보다 훨씬 더 많은 경쟁 제품들을 고려할 수도 있고, 기존에 오프라인에서 판매되고 있는 제품의 가격이 영향을 미칠 수도 있다. 따라서 구매 혹은 판매 상황에서 소비자들이 가격을 결정하는데 있어 영향을 줄 수 있는 요소에 대 한 보다 폭 넓은 고려가 필요할 것이다. 또한, 판매자의 입장에 해당하는 실험조건의 경우 실 제 보유했던 제품을 판매하는 것이 아니므로 기존 연구에서 제시된 소유효과(endowment effect)가 제한적으로 나타났을 가능성이 있다.

둘째, 본 연구에서는 제품 유형을 실용적 제 품과 쾌락적 제품으로 나누어 상황에 따른 소 비자 제시가격에 차이가 있음을 입증하였다. 그 러나 앞에서 언급한바와 같이 점점 실용적 속 성과 캐락적 속성이 흔합된 제품들이 나오고 있기 때문에 그 경계가 모호해지고 있다. 따라 서 실용적인 속성과 쾌락적 속성을 모두 가지 고 있는 제품을 구매하거나 판매할 때의 소비 자 제시가격은 어떻게 달라지는가에 대한 연구 가 필요할 것이다. 
셋째, 본 연구에서 선정한 제품인 '선글라스' 와 '전자사전'은 예비조사에서도 밝혔듯, 피 실 험자들에게 친숙도가 높은 제품들이었다. 따라 서 선글라스와 전자사전의 가격에 대한 피 실험 자들의 사전지식이 실험 상황의 가격 결정에 개 입됐을 가능성이 있다. 따라서 향후 연구에서는 가격 수준에 따른 다양한 제품들을 선정하여 이 러한 사전지식의 영향을 최소화할 필요가 있다.

넷째, 본 연구에서는 소비자의 목적 지향성을 향상 목적과 예방 목적으로 나누어 상황에 따 른 소비자 제시가격에 차이가 있음을 입증하였 다. 즉. 피 실험자들의 본래의 성향이 다 같다 는 가정 하에 그들의 목적 지향성을 각각 향상 목적과 예방 목적으로 프라이밍 시키는 방법으 로 설문조작을 하였다. 그러나 실제 소비자들은 이미 성립된 목적 지향성을 가지고 있을 수 있 고, 이러한 그들의 본래의 성향이 가격 결정에 영향을 미칠 수 있다. 따라서 향후 연구에서 소 비자들이 기존에 가지고 있는 목적 지향성이 직접적으로 나타나는 실험 방법을 개발할 필요 가 있을 것이다.

다섯째, 기존 연구(Pham and Higgins 2005) 에 의하면 예방목적의 경우 실용적속성에 좀 더 많은 주목을 하며, 높은 가중치를 두며, 많 은 프로세스를 하는 것으로 주장하고 있다. 즉 예방목적과 실용적 자극 간에는 목적 적합성이 존재한다는 주장이다. 아울러 향상목적의 경우 뢔락적 속성에 좀 더 많은 프로세스를 보인다 고 주장한다. 이는 본 연구에서 삼자간 상호작 용(three-way interaction)을 의미하는 것이다. 비록 본 연구에서는 삼자간 상호작용 효과가 통계적으로 의미 있게 나타나지 않았으나. 향후 연구에서 이러한 현상이 나타날 수 있는 가능
성은 배제할 수 없을 것이다.

끝으로. 본 연구에서는 일회성의 구매 상황이 나 판매 상황만을 살펴보았다. 하지만, 반복구 매가 이루어지는 실제 상황에서는 다른 결과가 나타날 수 있을 것이다. 따라서 향후 소비자가 같은 제품을 반복 구매 또는 판매하는 상황에 서 제시가격의 학습효과가 있는가에 대한 연구 가 필요할 것이다.

〈논문 접수일: 2007. 04. 11〉 〈게재 확정일: 2007. 12. 24〉

\section{참고문헌}

나준희(2004), “소비자의 조절적 동기가 구매 후 후회에 미치는 영향”, 한국심리학회지: 소 비자 · 광고, 5(1), 35-51.

여준상, 박종원, 김영조(2004), “규범초점이 브 랜드 확장평가에 미치는 영향," 한국소비문 화학희 춘계학술대희 발표논문집. 97-108. 이학식, 안광호, 하영원(2001), 소비자행동, 제3 판, 법문사.

Bar-Hillel, Maya and Efrat Neter(1996), "Why Are People Reluctant to Exchange Lottery Tickets?" Journal of Personality and Social Psychology, 70(January), 17-27.

Bohm, Gisela and Hans-Rudiger Pfister(1996), "Instrumental or Emotional Evaluations: What Determines Preferences?" Acta Psychologica, 93(1-3), 135-148.

Carmon, Ziv and Dan Ariely(2000), "Focusing on the Foregone: How Value Can Appear 
So Different to Buyer and Sellers," Journal of Consumer Research, 27(December), 360370.

Dhar, Ravi and Kaus Wertenbroch(2000), "Consumer Choice Between Hedonic and Utilitarian Goods," Journal of Marketing Research, 37(February), 60-71.

Heberlein, Thomas A. and Richard C. Bishop (1985), "Assessing the Validity of Contingent Valuation: Three Filed Experiment," paper presented at the International Conference on Man's Role in Changing the Global Environment, Venice, Italy.

Higgins, E. Tory(1997), "Beyond Pleasure and Pain," American Psychologist, 52(December), 1280-1300.

(1998). "Promotion and Prevention: Regulatory Focus as a Motivational Principle," in Advances in Experimental Psychology, Vol. 30, ed. Mark P. Zanna, San Diego, CA: Academic Press, 1-46.

Hirschman, Elizabeth C. and Morris B. Holbrook (1982), "Hedonic Consumption: Emerging Concepts, Methods and Propositions," Journal of Marketing, 46(Summer). 92-101.

Kahneman, Daniel and Amos Tversky(1979). "Prospect Theory: An Analysis of Decision under Risk," Econometrica, 47(March). 263-291.

- Jack L. Knetsch, and Richard Thaler(1990), "Experimental Tests of the Endowment Effect and the Coase Theorem," Journal of Political Economy. 98(6), 1325-1348.

Leclerc, Farnce, Bernd H. Schmitt and Laurette Dube(1994), "Foreign Branding and Its Effects on Product Perceptions and Attitudes," Journal of Marketing. Research, 31(May), 263-270.

Lockwood, Penelope, Christian H. Jordan and Ziva Kunda(2002), "Motivation by Positive or Negative Role Models: Regulatory Focus Determines Who Will Best Inspire Us." Journal of Personality and Social Psychology, 83(4), 854-864.

MacInnis, Deborah J. and Linda L. Price (1987), "The Role of Imagery in Information Processing: Review and Extensions," Journal of Consumer Research, 13(March). 473-491.

Pham, Michel Tuan and Higgins E. Tory (2005), "Promotion and Prevention in Consumer Decision Making: State of the Art and Theoretical Propositions," Inside consumption: Frontiers of research on consumer motives, goals, and desires, S. Ratneshwar, David Glen Mick, eds. Routledge. London, 8 - 43.

Thaler, Richard H.(1980), "Toward a Positive Theory of Consumer Choice," Journal of Economic Behavior and Organization, 1 (March), 39-60.

Simonson, Itarmar and Aimee Drolet(2004), "Anchoring Effects on Consumers' Willingness- 
to-pay and Willingness-to-Accept," Journal of Consumer Research, 31(December), 681690 .

Strahilevitz, Michal A and George F. Loewenstein (1998), "The Effect of Ownership History on the Valuation of Objects," Journal of Consumer Research, 25(December), 276289.

and John G. Myers(1998), "Donations to Charity as Purchase Incentives: How Well They Work Depend on What You Are Trying to Sell," Journal of Consumer Research, 24(March), 434446.
Tversky, Amos and Daniel Kahneman(1974), "Judgement under Uncertainty: Heuristics and Biases," Science, 185, 1124-1131. and Dale Griffin(1991), "Endowment and Contrast in Judgements of WellBeing," in Subjective Well-Being: An Interdisciplinary Perspectives, Fritz Strack, Michael Argyle, and Norbert Schwarz, eds. Oxford: Pergamon Press, 101-118. and Daniel Kahneman (1991), "Loss Aversion in Riskless Choice: A Reference-Dependent Model," Quarterly Journal of Economics, 106(November), 1039-1062. 


\section{〈부록〉}

\section{〈가상의 전자사전 제품 시나리오〉}

\begin{tabular}{|c|c|}
\hline & $\begin{array}{l}\text { 품명 : } 000 \text { 전자사전 } \\
\text { 국어사전 / 고사성어사전 / 활용옥편 / 한영/영한사전 / 영영사전 / 영어부가사전 / 한 } \\
\text { 일/일한사전 / 일본어부가사전 / 한중/중한사전 / 중국어부가사전 / TOEIC/TOEFL / } \\
\text { 영어회화사전 / 일본어회화사전 / 중국어회화사전 / } 2048 \mathrm{MB} \mathrm{/} \mathrm{컬러} \mathrm{/} \mathrm{TTS발음} \mathrm{/} \mathrm{멀} \\
\text { 티태스킹 / MP3 / FM라디오 / E-BOOK / 음성녹음 / U\&DIC } \\
\text { 가겨 : } 250,000 \text { 원 }\end{array}$ \\
\hline & $\begin{array}{l}\text { 품명 : } 000 \text { 전자사전 } \\
\text { 국어사전 / 고사성어사전 / 활용옥편 / 한영/영한사전 / 영영사전 / 영어부가사전 / 한 } \\
\text { 일/일한사전 / 일본어부가사전 / 한중/중한사전 / 중국어부가사전 / TOEIC/TOEFL } \\
\text { / 영어회화사전 / 일본어회화사전 / 중국어회화사전 / 컬러 / RealSpeak / 멸티태스 } \\
\text { 킹 / } \mathrm{MP3} \text { / FM라디오 / E-BOOK / 1.2GB내장메모리 / 차이코프스키검색 / } 4.3 \text { 형 } \\
\mathrm{TFT-LCD} \mathrm{/} \mathrm{빠른검색속도} \\
\text { 가격 : } 229,000 \text { 원 }\end{array}$ \\
\hline & $\begin{array}{l}\text { 품명 : } 000 \text { 전자사전 } \\
\text { 국어사전 / 고사성어사전 / 활용옥편 / 한영/영 한사전 / 영영사전 / 한일/일한사전 / } \\
\text { 일본어부가사전 / 한중/중한사전 / 영어회화사전 / 일본어회화사전 / 중국어희화사전 } \\
\text { / 다국어희화사전 / } 26 \text { 자x18행 / 컬러 / Vox Ward / 멀티태스킹 / E-BOOK / 음성 } \\
\text { 녹음 / 넷싱크지원 / 외부버튼채용 / 컬러 / 터치스크린 } \\
\text { 가젹: } 156,000 \text { 원 }\end{array}$ \\
\hline & $\begin{array}{l}\text { 품명 : } 000 \text { 전자사전 } \\
\text { 국어사전 / 활용옥편 / 한영/영한사전 / 영영사전 / 영어부가사전 / 한일/일한사전 / } \\
\text { 일본어부가사전 / 한중/중한사전 / 중국어부가사전 / TOEIC/TOEFL / 영어화화사전 } \\
\text { / 일본어회화사전 / 중국어회화사전 / 흑백 / 육성발음+TTS / 멀티태스킹 / 백라이 } \\
\text { 트 / MP3 / 음성녹음 / 마그네슘합금바디 / USB전자사전 / 한자획순애니메이션 } \\
\text { 가격 : } 130,000 \text { 원 }\end{array}$ \\
\hline & $\begin{array}{l}\text { 품명 : } 000 \text { 전자사전 } \\
\text { 국어사전 / 고사성어사전 / 활용옥편 / 한영/영한사전 / 영영사전 / 영어부가사전 / } \\
\text { 한일/일한사전 / 일본어부가사전 / 한중/중한사전 / 중국어부가사전 / JPT/EJU / 영 } \\
\text { 어회화사전 / 다국어회화사전 / 컬러 / Vox Ward / MP3 / FM라디오 / E-BOOK / } \\
\text { 자동절전기능 / 4.3형TFT-LCD / 이퀄라이저 } \\
\text { 가격: } 191,000 \text { 원 }\end{array}$ \\
\hline & $\begin{array}{l}\text { 품명 : } 000 \text { 전자사전 } \\
\text { 국어사전 / 활용윽편 / 한영/영한사전 / 영영사전 / 영어부가사전 / TOEIC/TOEFL } \\
\text { / 영어회화사전 / } 44 \text { 자x10행 / 흑백 / RealSpeak / 계산기능 / 기념일 / 스케줄 / } \\
186 \mathrm{~KB} \text { 풀래시메모리 } \\
\text { 가져: } 100,000 \text { 원 }\end{array}$ \\
\hline
\end{tabular}


〈가상의 선글라스 제품 시나리오〉

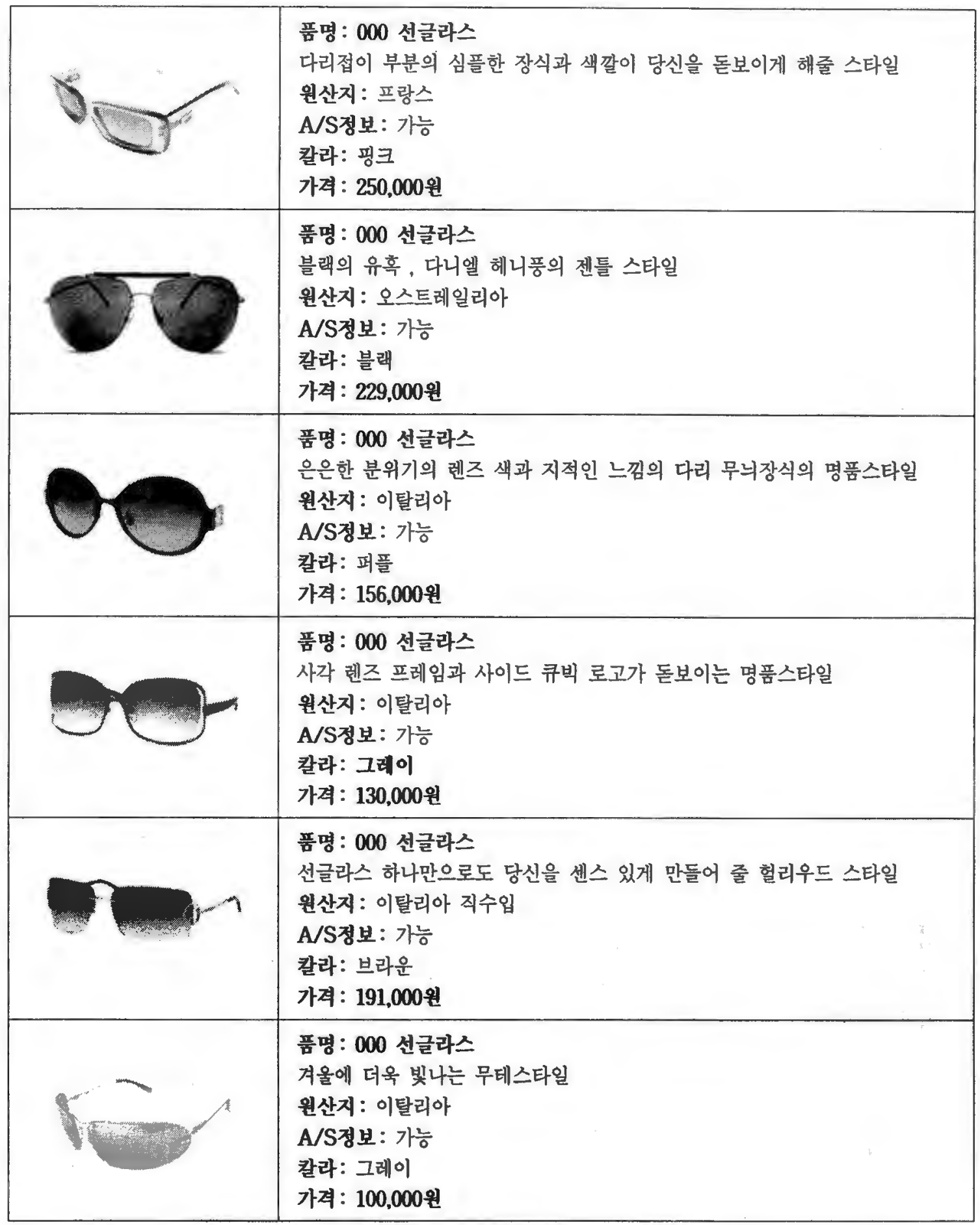




\section{〈구매상황 및 판매상황에서 제시된 전자사전 및 선글라스〉}

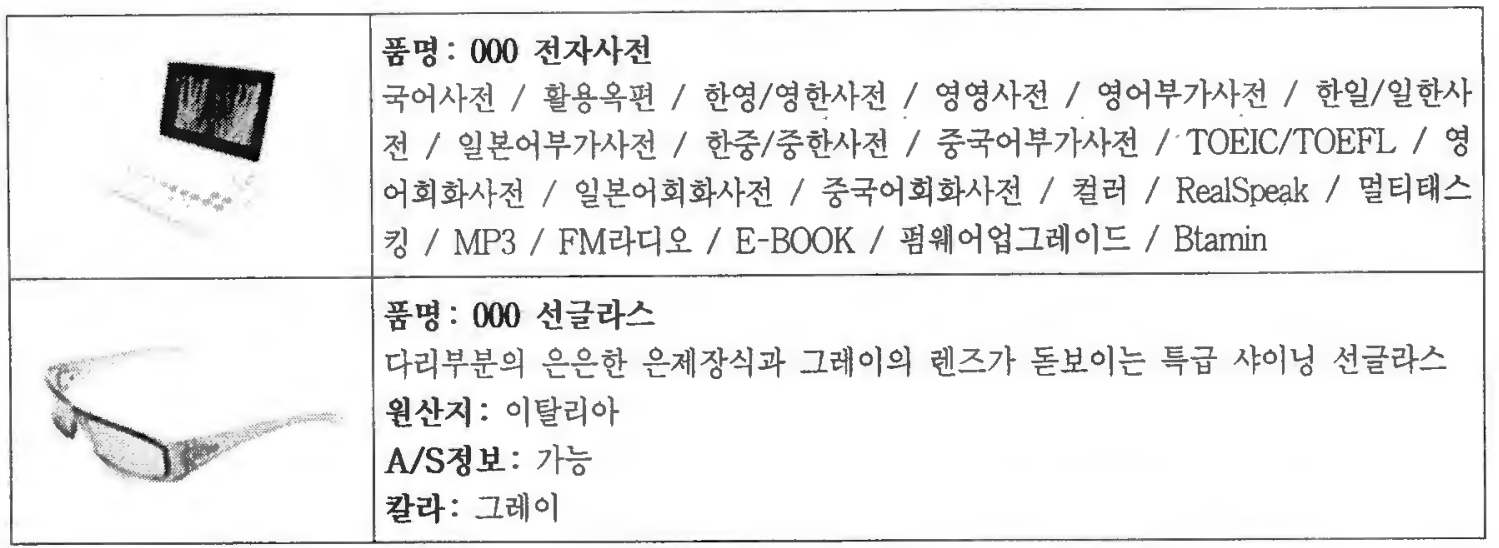




\title{
The Effect of Regulatory Focus and Product Type on the Difference in Acceptable Prices between Buyers and Sellers
}

\author{
Jun, Sung Youl* \\ Ju, Tae Wook** \\ Cho, Hyo Ryung***
}

\begin{abstract}
This study examines the generalizability of the existing research in an on-line auction situation which suggests that there exist a gap between buyer's willing-to-pay price(WTP) and seller's willing-to-sell price(WTS) about the same product due to the endowment effect and consumers' loss aversion propensity. At the same time, this study also identifies and examines the potential moderating factors for the effect such as product type and consumer's goal orientation based on existing theories about consumers' gain-loss heuristics.

The results show that WTS is consistently higher than WTP, and that such gap gets more pronounced when the target product is hedonic vs. utilitarian and when consumers have prevention goals vs. promotion goals. Lastly, limitations and managerial implications of this study is discussed.
\end{abstract}

Key words: price negotiation, willing-to-pay price, willing-to-sell pricet, utilitarian product, hedonic product, promotion goal, prevention goal

* Professor of Marketing, Sogang University

** Corresponding author, Doctoral student in Marketing, Sogang University

*** Graduated student in Marketing. Sogang University 


\section{Introduction}

According to existing researches, the price that a seller wants to accept(willing-to-sell price: WTS) for a product is different from the price that a buyer wants to pay(willingto-pay price: WTP). Several reasons for this difference between WTS and WTP include the psychological reason that seller and buyer perceive the value of the product from different perspectives, as well as the economical reason where a seller simply wants to gain more monetary benefit and a buyer wants less monetary loss(Bar-Hillel and Neter 1996; Herberlein and Bishop 1985; Kahneman and Tversky 1979; Kahneman, Knetsch, and Thaler 1990; Thaler 1980; Tversky and Kahneman 1991).

However, the gap between WTS and WTP don't always show up on scale. In some cases, the gap can be narrower but also broader. So, past research suggests that the reason for difference between WTS and WTP is due to a differential anchoring effect(Simonson and Drolet 2004).

Therefore, this study examines the generalizability of the existing research in an on-line auction situation which suggests that there exists a gap between WTP and WTS. At the same time, this study also identifies and examines the potential moderating factors for the effect such as product type and consumer's goal orientation.

\section{Theoretical Background and Hypothesis}

Past consumer researches show that there exist a gap between WTP and WTS about the same product due to the endowment effect and consumers' loss aversion propensity(BarHillel and Neter 1996: Kahneman and Tversky 1979; Tversky and Kahneman 1991: Thaler 1980). That is to say, according to the basic idea of consumer's loss aversion propensity letting of an item is more painful than not obtaining this same item. The gap between selling and buying prices reflects this difference in pain(Kahneman and Tversky 1979; Tversky and Kahneman 1991). Moreover. Carmon and Ariely (2000) states that consumers have a tendency to focus on forgone outcomes in exchange. Focusing on forgone outcomes, sellers focus on forfeiting the item whereas buyers focus on the expenditure. Buying prices tend to be more heavily influenced by reference prices, whereas selling prices tend to be more heavily influenced by forgoing possession of the product. So, some aspects of the exchange have higher on buying prices than on selling prices. We therefore propose the following hypothesis. 
H1: Willing-to-sell price(WTS) of a product will be higher than willing-to-pay price(WTP).

Product type(hedonic product versus utilitarian product) may moderate the effect of acceptable price according to negotiation condition. Hedonic products give an affective and sensory experience of aesthetic or sensual pleasure, fantasy, and fun, whereas utilitarian products give an instrumental and goal orient- ation and accomplish a functional and practical task (Lecterc, Schmitt and Dube 1994: Strahilevitz and Myers 1998).

These product types can have a influence on consumer's choice task. That is to say, When consumer choices between two products, one of which is seen as superior on a hedonic dimension and the other is seen as superior on a utilitarian dimension, whether the condition to acquire the product(acquisition choices) or the condition to give up(forfeiture choices) can give a differential effect to consumer's choice. So, the relative salience of hedonic dimension is greater when consumers decide which item to give up than when they decide which item to acquire(Dhar and Wertenbroch 2000). When consumers acquire a product, they search for reason and argument to justify their choice (Tversky and Griffin 1991), and this justification enhances preference for utilitarian product(Bohm and Pfister 1996).

That is to say, we expect that an utilitarian product which consumers easily find a justification of the value of a product enhance the value judgement of a target product as well as WTP compared with a hedonic product. It is because consumers have a tendency to find reasons and arguments to justify their choice when they purchase a product. In contrast, when consumers sell a hedonic product, they assess the value of a target product higher as they can imagine and sophisticate the loss caused by selling a product. In conclusion, the price of a hedonic product is more likely to have higher WTS. Therefore, we propose the following hypothesis.

H2: The difference between WTS and WTP will get more pronounced when the product is hedonic than utilitarian.

People's Motivational orientation to achieve their own desired end states can be divided into promotion goal and prevention goal. If people have a promotion goal, they focus on attaining positive consequences of decision alternatives, whereas if people have a prevention goal, they focus on avoiding negative consequences(Higgins 1997, 1998).

Therefore, if we examine the case which consumers have a promotion goal, they will have a tendency to lower WTS reflecting financial profit more than a loss on utility of a product when they sell it. In contrast, consumers are more sensitive to utility of a 
product than financial profit when they purchase a product. So, consumers will raise WTP in this case. On the other hand, if consumers have a prevention goal, they will have a tendency to raise WTS reflecting to a loss on utility of a product more than a financial profit. However, consumers will lower WTP as they are more sensitive to a financial loss when they purchase a product. Therefore, We propose the following hypothesis.

H2: The difference between WTS and WTP will get more pronounced when consumers have prevention goals than promotion goals.

\section{Experiment and Results}

In the present study, we tested these hypotheses by $2 \times 2 \times 2$ between subjects design. In the concrete we randomly assigned 264 students in university to one of the eight scenarios of a 2 (negotiation condition: buying versus selling) $\times$ 2(product type: hedonic versus utilitarian) $\times$ 2(goal orientation: promotion versus prevention) factorial design. We first describe the pretests carried out to develop the stimulus materials and experimental manipulations, and then describe the actual experiment.

H1 postulates that WTS of a product will be higher than WTP. The main effect between buying condition and selling condition is significant $(F(1,246)=16.586, p<.01$ : see Table 1). Table 1 reports that participants put the price high in selling condition $(M=236.484)$ than in buying condition( $M=201.262)$. Thus, $\mathrm{H} 1$ is supported.

$\mathrm{H} 2$ states that the difference between WTS and WTP will get more pronounced when the product is hedonic than utilitarian. The interaction effect between negotiation condition and product type is significant $(F(1,246)=$ 11.713, p <.01: see Table 1). A utilitarian product shows that the acceptable price of selling condition is 229,962 won and buying condition is 224,175 won, but a hedonic product shows that the acceptable price of selling condition is 244,775 won and buying condition is 178,059 won. So, the effect size is significantly greater in hedonic product than utilitarian product. Hence, H2 is supported.

$\mathrm{H} 3$ proposes that the difference between WTS and WTP will get more pronounced when consumers have prevention goals than promotion goals. The interaction effect between negotiation condition and consumer's goal orientation is significant $(F(1,246)=5.432, p<$ .05: see Table 1). When consumers have promotion goals, the acceptable price of selling condition is 226,036 won and buying condition is 210,530 won, but when consumers have prevention goals, the acceptable price of selling condition is 248,700 won and buying condition is 191.703 won. Therefore, the effect size is 
〈Table 1〉 Analysis of Variance(ANOVA) Results

Dependent Variable: Acceptable prices(a monetary unit: a thousand won)

\begin{tabular}{|l|c|c|c|c|}
\hline \multicolumn{1}{|c|}{ Source } & Mean & d.f. & MS & F-value \\
\hline $\begin{array}{l}\text { A. Negotiation condition : } \\
\text { Buying condition } \\
\text { Selling condition }\end{array}$ & & 1 & 83232.019 & $16.586^{* * *}$ \\
& 207.262 & & & \\
B. Product type: & 236.484 & & & \\
$\quad$ Hedonic product & 227.023 & 1 & 15515.549 & $3.092^{*}$ \\
$\quad$ Utilitarian product & 209.616 & & & \\
& & & & \\
C. Consumer's goal orientation: & 218.214 & 1 & 233.086 & 0.046 \\
$\quad$ Promotion goal & 218.715 & & & \\
Prevention goal & & 1 & 58777.237 & $11.713^{* * *}$ \\
\hline A $\times$ B & & 1 & 27257.384 & $5.432^{* *}$ \\
A $\times$ C & & 1 & 1152.685 & 0.632 \\
B $\times$ C & & 1 & 3859.553 & 0.381 \\
\hline A $\times$ B $\times$ C & & 246 & 5018.312 & \\
\hline Error & & & & \\
\hline
\end{tabular}

${ }^{*} \mathrm{p}<.1,{ }^{* *} \mathrm{p}<.05,{ }^{* * *} \mathrm{p}<.01$

significantly greater when consumers have prevention goals than promotion goals. Hence $\mathrm{H} 3$ is also supported.

\section{Conclusion}

This study verified the possibility of generalization in terms of consumer's WTP and WTS measured in existing studies through the situation of on-line auction which is a new distribution channel to consumers. We also aimed to expand the realm of existing studies by defining moderating variables and examining their effectiveness.

If we examine specific results of this study. firstly, we could generalize the existing study which shows WTS is higher than WTP (Simonson and Drolet 2004) in on-line auction which is new exchange situation. Secondly, we discovered that a gap between WTP and WTS changes according to the type of a product. In case of a hedonic product, price negotiation is more difficult because of low WTP but high WTS. Thirdly, a gap between WTP and WTS also changes according to consumer's motivational orientation. If con- 
sumers have a prevention goal, price negotiation is more difficult because of low WTP but high WTS.

〈received: 2007. 04. 11〉

〈accepted: 2007. 12. 24〉

\section{Reference}

Bar-Hillel, Maya and Efrat Neter(1996), "Why Are People Reluctant to Exchange Lottery Tickets?" Journal of Personality and Social Psychology, 70(January), 17-27.

Bohm, Gisela and Hans-Rudiger Pfister(1996), "Instrumental or Emotional Evaluations: What Determines Preferences?" Acta Psychologica, 93(1-3), 135-148.

Carmon, Ziv and Dan Ariely(2000), "Focusing on the Foregone: How Value Can Appear So Different to Buyer and Sellers," Journal of Consumer Research, 27(December), 360-370.

Dhar, Ravi and Kaus Wertenbroch(2000), "Consumer Choice Between Hedonic and Utilitarian Goods," Journal of Marketing Research, 37(February), 60-71.

Heberlein. Thomas A. and Richard C. Bishop (1985), "Assessing the Validity of Contingent Valuation: Three Filed Experiment," paper presented at the International Conference on Man's Role in Changing the Global Environment, Venice,
Italy.

Higgins, E. Tory(1997), "Beyond Pleasure and Pain," American Psychologist. 52(December), 1280-1300. (1998), "Promotion and Prevention: Regulatory Focus as a Motivational Principle," in Advances in Experimental Psychology, Vol. 30, ed. Mark P. Zanna, San Diego, CA: Academic Press, 1-46.

Hirschman, Elizabeth C. and Morris B. Holbrook(1982), "Hedonic Consumption: Emerging Concepts, Methods and Propositions," Joumal of Marketing, 46(Summer), 92-101.

Kahneman, Daniel and Amos Tversky(1979), "Prospect Theory: An Analysis of Decision under Risk," Econometrica, 47(March), 263-291.

Jack L. Knetsch, and Richard Thaler(1990), "Experimental Tests of the Endowment Effect and the Coase Theorem," Journal of Political Economy, 98(6), 1325-1348.

Leclerc, Farnce, Bernd H. Schmitt, and Laurette Dube(1994), "Foreign Branding and Its Effects on Product Perceptions and Attitudes," Journal of Marketing. Research, 31(May), 263-270.

Lee. Hak-Sik, Kwang-Ho An, and YoungWon $\mathrm{Ha}(2001)$, Consumer Behavior, 3rd ed, Paju: Bobmunsa.

Lockwood, Penelope, Christian H. Jordan, and 
Ziva Kunda(2002), "Motivation by Positive

or Negative Role Models: Regulatory Focus Determines Who Will Best Inspire Us." Journal of Personality and Social Psychology, 83(4), 854-864.

MacInnis, Deborah J. and Linda L. Price (1987). "The Role of Imagery in Information Processing: Review and Extensions," Journal of Consumer Research, 13(March), 473-491.

Na, June-Hee(2004), "The Role of Consumer's Regulatory Focus on Postpurchase Regret," Korean Journal of Consumer and Advertising Psychology, 5(1), 35-51.

Pham, Michel Tuan and Higgins E. Tory (2005), "Promotion and Prevention in Consumer Decision Making: State of the Art and Theoretical Propositions," Inside consumption: Frontiers of research on consumer motives, gaals, and desires, S. Ratneshwar, David Glen Mick, eds. Routledge, London, 8 - 43.

Thaler, Richard H.(1980), "Toward a Positive Theory of Consumer Choice," Journal of Economic Behavior and Organization, 1 (March), 39-60.

Simonson, Itarmar and Aimee Drolet(2004), "Ancharing Effects on Consumers' Willingnessto-pay and Willingness-to-Accept," Journal of Consumer Research, 31(December), 681-690.
Strahilevitz, Michal A. and George F. Loewenstein (1998), "The Effect of Ownership History on the Valuation of Objects," Journal of Consumer Research, 25(December), 276289. and John G. Myers(1998), "Donations to Charity as Purchase Incentives: How Well They Work Depend on What You Are Trying to Sell," Journal of Consumer Research, 24(March), 434446.

Tversky, Amos and Daniel Kahneman(1974), "Judgement under Uncertainty: Heuristics and Biases," Science, 185, 1124-1131.

and Dale Griffin(1991),

"Endowment and Contrast in Judgements of Well-Being," in Subjective Well-Being: An Interdisciplinary Perspectives, Fritz Strack, Michael Argyle, and Norbert Schwarz, eds. Oxford: Pergamon Press, 101-118.

and Daniel Kahneman (1991), "Loss Aversion in Riskless Choice: A Reference-Dependent Model," Quarterly Journal of Economics, 106(November), 1039-1062.

Yeo, Jun-Sang, Jong-Won Park, and Young-Jo Kim(2004), "The Influence of Regulatory Focus on Brand Extension Evaluation," at Spring Conference in Korea Consumption Culture Association, 95-108. 